\title{
European Environment Agency still in limbo
}

London. When Carlo Ripa di Meana, the environmental commissioner of the European Communities (EC), announced that he would not be going to the current Earth Summit in Rio de Janeiro because environmental policies should be "based on binding obligations and precise undertaking, not on words", he might as well have been talking about events closer to home. Two years after the European Environment Agency (EEA) was created, its only outcome has been angry words, specifically a continuing political squabble about where it should be located and what it should be doing.

A report published last week by the British government's Advisory Council on Science and Technology (ACOST)* deplores a situation in which negotiations about the site of the European Parliament have stood in the way of the EEA starting on its job of collecting, collating and issuing environmental data. To make matters worse, the EC's existing programme for gathering environmental data was brought to a halt when the staff responsible were transferred to the task force that was supposed to set up the agency.

Fortunately, that task force, led by the EC's Philip Bourdeau, has managed not only to lay the foundations for the EEA but also to continued the work of CORINE (the information system on the state of the environment in Europe). Although the task force is thus carrying out part of the agency's intended function, one important element of what the EEA could do is still missing.

"The EEA has a primary responsibility to be the repository of environmental data for Europe", says Robert May, chairman of the ACOST working party on environmental research programmes. "But rather than just taking the data it is offered, it should also be thinking about what data are needed."

The EEA was never intended to fund research. But its creators hope that it will eventually have the ability to direct environmental monitoring and research programmes to fill gaps in the European dataset. By the same token, it could reduce the duplication of work that arises where nationally coordinated programmes meet at borders and set standards to ensure the compatibility of data from different sources.

Several European countries, notably the Netherlands, recognize the need for comprehensive registers of monitoring within their borders and have taken steps towards achieving that aim. However, without the EEA or a similar agency, the result is a patchwork of unrelated information.

Although individual nations have differing perceptions of the division between research and routine monitoring, data from both activities would feed into the EEA, and everyone would benefit from the baseline data that the EEA would provide. So although arguments may arise over who should fund which part of the work and whether the $\mathrm{EC}$ is spending its money wisely, there is every reason for the EEA to proceed.

The ACOST report also recommends, in addition to establishing a register of environmental monitoring activities, that Britain increase spending on local and regional environmental research and shift the emphasis from physical processes to the impact of environmental change. In particular, it calls for more research on understanding how physical and chemical changes in the environment affect and are affected by biological processes.

Bourdeau is hopeful that the European heads of state will address some of these issues at their summit meeting later this month. But it should be remembered that Britain, which will be taking on the presidency of the EC at that summit, just two months ago abandoned plans to establish its own environmental agency. Ian Mundell

* Environmental Research Programmes, by the Advisory Council on Science and Technology (HMSO, PO Box 276, London SW8 5DT, or call 44-71-873 9090).

\section{Eureka welcomes first East European member}

Paris. Hungary has become the first East European member of Eureka, the hightechnology programme of the European Communities (EC). Filippo Pandolfi, vice president and head of research for the EC, announced the decision two weeks ago at a Eureka meeting in Tampere, Finland, that coincided with the rotation of the programme's presidency from Finland to France.

Last June, Eureka announced that it would extend membership to countries in Eastern Europe. Since then, Eureka has established contacts with Hungary, Poland, the Czech and Slovak Federal Republic, Romania, Estonia, Lithuania, Albania, Slovenia and the countries of the Commonwealth of Independent States (CIS). Eureka officials say that they expect Poland and the Czech and Slovak Federal Republic to become full members of Eureka within the next 12 months, although neither country has yet applied formally.

Although non-member countries can take part in Eureka projects, the entrance criteria are more restrictive than for members. The new partner must take a major role in the project, and research must be carried out mainly in the member countries. Adminis- trative procedures are also more cumbersome. In 1991, some 17 Eureka participants in 10 projects were from East Europe.

Hungary, the first East European country to have officially applied for membership, has been involved with Eureka for longer than any of its neighbours. It is also the first country to meet such entrance requirements as having "an active market economic policy" and national research institutes and companies that have been involved with Eureka.

Hungary is expected to participate more fully in existing Eureka projects now that it is a full member; it already has limited involvement in several Eureka projects under the rules for outside participation. In the longer term, access to the Eureka network of Western companies, institutes and research projects should help Hungary to build research networks, break into new markets and commercialize its technologies. Eureka membership also improves the chances of Hungarian companies obtaining cash from their government for research. In turn, Hungary will begin to contribute to Eureka, paying as much as 35 per cent of any project in which it participates.

This enlargement of Eureka illustrates the continuing expansion of the frontiers of European research programmes. Last year, the European Commission opened up all of its Environmental Research Programme to the countries of eastern Europe, and admitted Hungary, Poland and the Czech and Slovak Federal Republic to the EC's COST (Co-operation in Science and Technology) programme.

Some issues relating to participation remain unresolved, however, a result of differing research philosophies. Eureka, with a tiny secretariat in Brussels, helps companies seeking government funding to develop their ideas for joint projects. Most of the projects in the EC's Framework programme, on the other hand, are designed by the commission and then carried out by consortia.

Industry would like the EC to put more money into Eureka, but the EC wants Eureka to remain independent. Despite those differences Eureka and the EC agree that the EC should co-fund Eureka projects where there is a link with the EC's precompetitive programmes, and that researchers in other EC projects should be encouraged to develop this research further within Eureka to foster its commercial applications.

David Bakewell 